\title{
Cli-Fi e narrativas distópicas do futuro:
}

\author{
O espaço da ironia em Downsizing
}

\section{Cli-Fi and dystopian narratives of the future:}

\section{The space of irony in Downsizing}

\section{Antonio Hélio Junqueira}

Doutor em Ciências da Comunicação (ECA/USP), com pós-doutorado em Comunicação e Práticas de Consumo pela ESPM. Universidade Federal do Paraná, Programa de Pós-Graduação em Gestão da Informação, Curitiba (PR), Brasil.

\section{Introdução}

Downsizing - traduzido no Brasil como Pequena grande vida - é um longa-metragem norteamericano da Paramount Pictures, de 2017, dirigido por Alexander Payne, com roteiro compartilhado com seu parceiro de outras iniciativas Jim Taylor. Trata-se de ficção científica que narra as possibilidades, efeitos e consequências da aplicação de um processo ultratecnológico de miniaturização de pessoas para versões de si mesmas reduzidas à dimensão máxima de pouco mais de alguns centímetros, na exata relação escalar de $1 / 12$.

Na sua diegese, a trama se desenrola dez anos após a consolidação tecnológica de complexos processos que resultam na miniaturização humana, descobertos e desenvolvidos por cientistas noruegueses liderados pelo fictício Dr. Jorgen Asbjornsen (vivido por Rolf Lassgard). No período narrativo, as práticas da diminuição já se encontravam relativamente dispersas em múltiplas microcolônias distribuídas por 
diferentes partes do mundo, e o incentivo à sua expansão seguia estimulado por iniciativas mercadológicas em larga escala, impulsionado, ainda, por incentivos tributários e fiscais.

A sustentação da adesão de muitos indivíduos ao uso aplicado da florescente tecnologia é discursivamente dada pelo desejo de reduzirem o volume material e financeiro do seu consumo de bens e serviços, alentados pela perspectiva de que, com isso, acarretariam menores níveis de impacto e dano sobre o já combalido meio ambiente global. No entanto, o motivo subjacente principal - e que instaura a perspectiva e a dinâmica do jogo irônico na trama do filme - é o do encontro de uma saída para que diferentes perfis de indivíduos e de famílias possam ter acesso ou seguirem consumindo toda sorte de mercadorias sem se preocuparem com as mazelas do trabalho escravizante para a obtenção de recursos necessários nem, tampouco, com o esgotamento dos recursos naturais do planeta em suas inextricáveis correlações com a geração interminável de lixo, descarte e poluição (BAUMAN, 2008; MARQUES FILHO, 2018). A essas incômodas questões é dada uma resposta técnico-científica simples: a redução do tamanho das pessoas e, consequentemente, de todos os bens consumidos. Os efeitos esperados são, então, o da substancial redução das quantidades de recursos necessários à produção de mercadorias idênticas às consumidas no mundo não miniaturizado e o da consequente minimização, ainda que tardia, do impacto ambiental decorrente.

O artigo explora a narrativa dessa obra ficcional situando-a no contexto das narrativas distópicas sobre o futuro, especialmente no contexto do subgênero denominado cli-fi (climate fiction). Destacando seu caráter paradoxalmente cômico, a análise avança apontando para a crítica das resistências humanas às mudanças de suas práticas de consumo consolidadas e superestimuladas no contexto do capitalismo neoliberal contemporâneo, mesmo que às custas de uma - ainda que frágil - consciência sobre o comprometimento da sobrevivência planetária. Trata-se de uma investigação que leva em conta os comentários de Terry Eagleton (1993), em A ideologia da estética, sobre o malicioso na obra schopenhaueriana, ao considerar que "a comédia é a zombeteira vingança da vontade sobre a representação [...], mas essa fonte de hilaridade é também, curiosamente, a raiz de nossa imensa desesperança" (p. 116). Dessa perspectiva, Downsizing tece uma narrativa imersa em redes de ironia, paródia e riso enquanto acontecimentos discursivos que operam para expressar ambiguidades, tensões e contradições do comportamento humano. 


\section{Cli-fi (climate fiction) como subgênero da ficção científica (sci-fi)}

No cenário artístico contemporâneo - especialmente na literatura e no cinema -, as narrativas distópicas do futuro, sob a forte ameaça de catástrofes cada vez mais iminentes, revestem-se crescentemente de caráter ecoapocalíptico em suas dimensões planetárias. Nesse contexto, emerge o subgênero denominado - no jargão midiático da crítica e do jornalismo literários - de ficção climática ou, na sua forma resumida, cli-fi (climate fiction).

As iniciativas nesse sentido, em sua maioria, empreendem narrativas amedrontadoras e tanto mais sinistras quanto mais verossímeis a respeito do futuro distópico e pós-apocalíptico do destino da humanidade e, possivelmente, de toda a natureza e da Terra. Trata-se de histórias construídas a partir dos riscos das dominâncias dos poderes totalitários ${ }^{1}$, das mutações biológicas e transgenias induzidas, de práticas predatórias da indústria e dos mercados $^{2}$ e das irracionalidades, vaidades, frivolidades e inconsequências do comportamento humano ${ }^{3}$. Raramente, contudo, narrativas no universo desse subgênero assumem o caráter leve da comédia e da ironia paródica, o que faz de Downsizing um objeto de particular interesse de análise.

A ficção científica - termo forjado em 1929 pelo inventor, editor e escritor Hugo Gernsback - veio a designar um gênero particular de narrativa em que elementos simbólicos da ciência e da técnica sustentam as criações artísticas, engendrando verossimilhanças e instituindo diegeses em suas próprias lógicas e em seus sentidos culturais (JUNQUEIRA, 2020). Não se pode cobrar dela, posto que não é da sua esfera de propósitos e competências, o fornecimento de respostas plausíveis, seguras, válidas e cientificamente comprováveis aos problemas, dilemas e demandas da humanidade. Por outro lado, é atestável seu valor social enquanto produto simbólico capaz de gerar chaves sígnicas para interpretação da realidade presente, portadoras de contribuições para as reflexões sobre o futuro da humanidade, bem como a respeito dos papéis e sentidos da ciência e da técnica.

Kim Stanley Robinson (2019), diretor do aclamado Nova York 2140, filme distópico sobre o futuro, também de 2017, fornece pistas relevantes nesse sentido:

\footnotetext{
${ }^{1}$ Cf. Margareth Atwood (The handmaid's tale, 1985; Oryx and Crake, 2003; The testaments, 2019).

${ }^{2}$ Cf. Kim Stanley Robson (Nova York 2140, 2017).

${ }^{3}$ Cf. Ian McEwan (Solar, 2010).
} 
enquanto o aquecimento global vem se tornando um dos problemas centrais de nossos tempos, talvez o central, uma cruz na história humana e planetária, as pessoas precisam da fiç̧ão para ajudá-las a pensar sobre isso. É simplesmente uma necessidade cultural, um tipo de fome: nós sempre queremos e precisamos de arte para interpretar a realidade e criar significado (CÁCERES, 2020, p. H3).

Nesse contexto, a ficção científica muitas vezes assume formas e narrativas alegóricas e especulativas sobre o presente e o futuro, podendo transformar-se em portadora de possibilidades e/ou de advertências políticas, morais e comportamentais ao sinalizar para possíveis cenários indesejáveis e evitáveis que envolvem, de maneira especial, o ambiente científico e tecnológico. Nessa direção, costuma comportar perspectivas utópicas, ao buscar conformar olhares e práticas focadas em um melhor futuro tanto pelo que fazemos e faremos quanto pelo que podemos deixar de fazer.

Por outro lado, tem sido cada vez mais recorrente, também, a instauração de perspectivas distópicas sobre o futuro, forjadas pelas mais sombrias perspectivas das catástrofes ecológicas presentemente vivenciadas e ameaçadoramente previstas (GORE, 1993; GIDDENS, 2010; KLEIN, 2014; STENGERS, 2015; MARQUES FILHO, 2018). Nesses casos tem sido facilmente identificável a prevalência de visões incrédulas e desesperançadas sobre a capacidade humana de regeneração e mudança - e, portanto, pessimistas a respeito do próprio futuro da humanidade. Para Sfez (1996), a regeneração eco-bio-religosa do mundo, capaz de reconectar em fusão perfeita o mundo e o indivíduo, representa a mais perfeita e a última utopia contemporânea.

O filme ora analisado, a rigor, enquadra-se na perspectiva das narrativas distópicas, especialmente pela ênfase que confere à incapacidade e à decidida má vontade dos seres humanos para com a sua própria transformação frente à dócil submissão às vicissitudes do consumismo. No entanto, o tom leve e cômico que caracteriza a sua narrativa lhe assegura um lugar de particular interesse analítico.

Em Downsizing, o principal eixo crítico - e subliminar - que o torna paródico e risível é o fenômeno da resistência absoluta do sujeito ao questionamento e eventualmente à revisão do seu estilo de vida, mesmo alegando preocupações com a saúde do meio ambiente e com a sobrevivência global de humanos e não humanos. Nesse sentido, a opção pela miniaturização converte-se em saída valiosa para a manutenção do status quo e, mais importante ainda, para o acesso expandido ou até mesmo ilimitado ao consumo, à luxúria e aos prazeres intermináveis. 
Todos os recursos financeiros previamente acumulados no mundo dos cidadãos normais - leia-se: não miniaturizados - podem ser transpostos e convertidos com larga margem de ganho no mundo de Lazerlândia (Leisureland) - a colônia miniaturizada onde se desenrola a trama fílmica -, pelas novas relações do dinheiro com os nascentes valores de troca (100 mil dólares viram 12 milhões). Nessa direção e sentido, as promessas do novo pequeno mundo e da nova pequena vida são desenhadas na conformação de cotidianos e de rotinas de lazer permanente, em uma espécie de presente eterno para os deleites do consumismo.

Desde a estreia oficial do filme, a crítica especializada, via de regra, foi pródiga em apontar grande quantidade de imperfeições e carências na obra, principalmente frente às expectativas geradas pela reputação do autor, que contou com três indicações ao Oscar de melhor diretor e outras três de melhor roteiro, consagrado por produções anteriores como Nebraska, filme de 2013, de sucesso notável em Hollywood. Entre as críticas mais recorrentes, observam-se o apontamento para o excesso de personagens secundários que aparecem e desaparecem com certa leviandade narrativa ao longo do enredo, a multiplicação de cenas extensas de pouca relevância na trama (como a sequência inicial do convívio do personagem principal com a mãe cronicamente doente) e a ingenuidade constrangedora de algumas sequências como a do pôr do sol acompanhado pela colônia norueguesa original, na iminência de sua migração para um abrigo subterrâneo onde permanecerão por 8000 anos, na perspectiva de com isso salvarem a espécie humana da sua mais completa extinção.

Em sentido contrário, comentários e avaliações elogiosas foram abundantes em relação às primorosas cenas do encolhimento das pessoas, bem como das relações que se estabelecem entre indivíduos encolhidos e não encolhidos, e entre aqueles e os objetos cotidianos. O extremado cuidado dado às narrativas sobre as necessidades de eliminação dos cabelos e pelos corporais e especialmente dos dentes, posteriormente reimplantados na escala conveniente ao novo padrão de altura, gera efeitos de verdade e credibilidade na técnica reducionista, contribuindo para uma narrativa ficcional bem-sucedida.

Independentemente de aspectos como esses, que se reportam à esfera da elaboração artística e artesanal do filme, nossa análise caminha em direção às críticas explícitas e implícitas na discursividade da narrativa, ressaltando seu caráter intertextual metafórico. 
A liberdade da criação artística permite o estabelecimento do diálogo do autor com a tessitura e as possibilidades próprias da linguagem, para além da realidade aparente do mundo. Abrem-se, aí, diversos caminhos, incluindo os das paródias, estilizações, paráfrases e apropriações, das quais o filme analisado se mostra repleto (SANT'ANNA, 2003).

No pensamento bakhtiniano (BAKHTIN, 1995, 2010), o riso constitui-se em fenômeno que se dá na linguagem, na vida e na História e que se revela no e pelo discurso. Nesse contexto, a paródia instaura-se como potente estratégia capaz de engendrar profusão de gêneros discursivos, que vem assim conferir lugar ao riso tanto no interior das culturas populares quanto nas eruditas. Podemos assim pensar o riso da comédia ou da paródia como acontecimento que transita tanto entre as linguagens do cotidiano quanto entre as linguagens da arte.

\section{As múltiplas dimensões e sentidos do encolhimento}

Na esfera da ficção literária e cinematográfica, o encolhimento humano tem sido tema recorrente em narrativas em diferentes frentes, com destaque especial para a literatura infantil e o gênero aventura. As histórias mais conhecidas, contadas e recontadas, certamente são as As viagens de Gulliver, um bestseller da literatura inglesa, de autoria de Jonathan Swift, publicado originalmente em 1726, e As aventura de Alice no País das Maravilhas obra de Charles Lutwidge Dodgson, publicada em 4 de julho de 1865 sob o pseudônimo de Lewis Carroll.

No cinema, obras de destaque no gênero podem ser encontradas em $O$ incrivel homem que encolheu (The Incredible Shrinking Man, 1957), inspirado no romance homônimo de Richard Matheson publicado em 1956, que narra as aventuras e desventuras de um homem que, ao ser exposto à radiação e a produtos vermicidas, começa a encolher. Nessa obra, o drama se estabelece na busca do personagem por um modo de reverter o processo, sob pena de seguir diminuindo até seu completo desaparecimento. Outro exemplo é o da comédia leve e divertida Querida encolhi as crianças (Honey, I Shrunk the Kids), de 1989, que engendrou continuidades em outros filmes dele derivados.

O imaginário do encolhimento humano comporta várias leituras, e suas abordagens artísticas quase sempre estão envoltas pelas possibilidades imanentes da reversão do processo ou de mudanças radicais dos 
contextos em que ocorrem: Alice encolhe e estica várias vezes ao longo de suas aventuras; Gulliver é um gigante para os liliputianos, mas se torna ele mesmo uma miniatura em Brobdingnag.

Diferentemente, a narrativa em Downsizing não visa o entretenimento infantil nem disputa o interesse no gênero aventura. Nela, além disso, o processo do encolhimento é irreversível, e o mundo habitado é o mundo humano contemporâneo e reconhecível, partilhado simultaneamente por gentes grandes e minúsculas, em todos os seus dilemas econômicos, sociais, morais, políticos e ambientais.

No filme, o processo do encolhimento dialoga com múltiplas intertextualidades pautadas especialmente pela crítica do consumismo contemporâneo e das ameaças que dele decorrem para a saúde, se não mesmo para a própria sobrevivência da vida humana e de todo o planeta.

Nessa direção e sentido, um primeiro eixo analítico pode ser encontrado nas suas conexões com temas e movimentos do ativismo social que apontam para o decrescimento econômico e para a necessária redução dos padrões e estilos de consumo em escala planetária.

O conceito político e econômico do decrescimento foi originalmente formulado por André Gorz na década de 1970, sob influência das teses bioeconômicas do matemático romeno Nicholas GeorgescuRoegen. Tal formulação é sustentada pela perspectiva da insustentabilidade do crescimento constante do produto econômico (Produto Interno Bruto - PIB) em escala global. Dessa perspectiva, a produção e o consumo não podem crescer indefinidamente, na mesma medida em que os recursos naturais são finitos.

Serge Latouche (2012), professor emérito de Economia na Universidade de Orsay, França, tem sido um dos mais destacados teóricos defensores da teoria do decrescimento. Suas abordagens e propostas se sustentam no reconhecimento da profunda crise ecológica vivenciada em escala global na contemporaneidade e da inviabilidade, nesse contexto, da insistência no imaginário da sociedade do crescimento infinito. Trata-se, para o autor, de viabilizar formas de enfrentamento radical que tal ordem de coisas impõe ao coletivo social e que se materializam de forma crescente na exclusão, na desigualdade, na miséria e na espoliação. No arcabouço de seu ideário encontram-se as contribuições de Jacques Ellul (1963) e Ivan Illich (1973), focadas nas propostas de repensar as bases imaginárias da sociedade de consumo em seu tripé de sustentação: o progresso, a ciência e a técnica. 
A crítica que emerge da ironia de Downsizing é a da recusa humana em abrir mão dos seus desejos de consumo e da vontade de adesão a estilos de vida suntuosos e conspícuos, mesmo no caso de cidadãos trespassados por discursos sobre a insolvência planetária e os riscos iminentes de uma catástrofe global. Nesse contexto, o decrescimento não decorre (e não pode decorrer) da redução do consumo e de seus apetites, que permanecem intocáveis ou ainda mais insaciáveis; ocorre pela única via então possível: a redução da escala humana. A pulsão consumista não arrefece, e experimenta, até mesmo, irrefreadas expansões. A redução da exploração e dos danos ambientais advindos do consumo torna-se mera questão de proporção, assim como também os esforços do trabalho para a obtenção da renda para os gastos nos mercados. Nesse contexto, imagina-se que o mundo consumirá menos não porque foi capaz de reorientar suas ideologias e práticas sociais, mas apenas porque as quantidades das matérias-primas e produtos foram minimizadas por uma simples equação de conformidade escalar.

As conexões paródicas que aí se estabelecem corroboram o funcionamento da linguagem do riso, fortalecendo o jogo das ambiguidades que sustentam e denunciam "o fracasso do poder constituído, numa sociedade cheia de contrastes" (ARAGÃO, 1980, p. 19-21)

\section{As máquinas autopoiéticas e a produção das subjetividades}

O conceito da máquina autopoiética foi desenvolvido pelos biólogos Humberto Maturana e Francisco Varela no final do século XX. Visava a racionalização científica dos processos de autoprodução dos seres vivos a partir da reprodução celular, bem como da criação permanente de sua estabilidade a partir de dinâmicas de interação com as mudanças e perturbações do ambiente, sustentadas por uma inexorável manutenção da auto-organização, típica dos sistemas complexos. A essa ideia, os autores atribuíram a denominação de "clausura operacional” (MATURANA; VARELA, 1998).

Félix Guattari (1976) se apropriou do conceito de máquina autopoiética desses autores ampliando-o para o entendimento da realidade social cotidiana, na sua autoprodução dos modos da existência. $\mathrm{O}$ autor afasta-se, portanto, das visões mecanicistas e termodinâmicas das engrenagens viscerais do conceito original da máquina autopoiética para abranger as complexidades do universo social. Para Guattari (1976), o sistema maquínico serve ao estudo das dinâmicas da subjetivação, capazes de engendrar novos modos de viver e de pensar a realidade-mundo. O aprofundamento desse conceito, em parceria com Gilles Deleuze, 
conduziu o autor à formulação das perspectivas do agenciamento coletivo necessário e desejável à produção e experimentação de novas realidades possíveis, em processos existenciais de formulação e invenção de novas subjetividades (DELEUZE; GUATARRI, 1977).

No âmbito deste artigo, a inclusão da perspectiva guattariana da teoria da máquina autopoiética serve ao propósito de evidenciar a emergência irônica da narrativa de Downsizing, ao denunciar que, mesmo sujeita a processos radicais de alteração de organização sistêmica do corpo biológico, a humanidade tende a se manter subjugada - e não resistente - aos ditames ideológicos do capitalismo neoliberal contemporâneo, condição sob a qual não consegue ou não se permite ser seduzida pela produção potencial do inédito social. Negando-se à criação e vivência de novas subjetividades, os sujeitos e suas microcomunidades, em Downsizing, sucumbem à mera reprodução dos sentidos, valores e (in)sensibilidades que - ao menos na ilusão dos discursos - motivaram as decisões do encolhimento. O mundo, enfim, pode ser decrescido nas suas escalas físicas, mas reproduz as exatas dimensões das inequidades, injustiças e desgraças sociais.

\section{O loser $^{4}$ norte-americano}

O personagem principal de Downsizing, Paul Safranek (vivido por Mat Damon), é o típico loser desenhado pelo capitalismo liberal no âmbito da cultura norte-americana. O loser é, nesse contexto, a outra face da moeda do self-made-man, bem-sucedido exemplar do empreendedorismo de si, ao qual o neoliberalismo não cansa de entoar entusiasmadas loas; é o sujeito falido, fracassado, ameaçado pelos iminentes estigma e apagamento social. A dimensão mais trágica do loser é o seu aprisionamento a uma identidade social que o acorrenta à subalternidade e à frustração permanente frente à impotência para conquistar os objetos de sua inquieta e insone ambição de consumo (SANDAGE, 2005).

Embora esforçado, trabalhador, ponderado e econômico - como todo loser típico -, Paul vai aos poucos adquirindo consciência de que jamais conseguirá juntar dinheiro suficiente para adquirir os bens com

\footnotetext{
${ }^{4}$ Mantivemos o termo original em inglês porque consideramos que não existe uma tradução suficiente para o significado que o termo possui na língua matriz. Além disso, a palavra foi forjada no contexto da cultura capitalista neoliberal norte-americana, em que encontra a sua máxima expressão sígnica.
} 
que ele e sua esposa, Audrey Safranek (Kristen Wiig), tanto sonham, principalmente uma mansão de luxo e seus objetos e estilo de vida correlacionados e decorrentes.

Esse se torna, de fato, o gatilho principal da decisão do casal Safranek em abandonar sua vida mediocrizada na cidade de Omaha e migrar, miniaturizado, para a colônia de Lazerlândia. Vale destacar, contudo, que na sequência narrativa a esposa Audrey desiste do processo de encolhimento, condenando Paul a seguir em frente no projeto sozinho e irreversivelmente transmutado.

Ao longo do filme, Paul reafirma sua inexorável identidade loser, tendo suas finanças reduzidas pelo divórcio e pela impossibilidade de exercer sua antiga profissão, haja vista que o novo ambiente reproduz a burocracia do mundo anterior, não reconhecendo seus registros profissionais para o trabalho em outro estado - o Novo México, no caso. Fracassado, Paul assume ironicamente serviços destinados a atender, via call center, os desejos, insatisfações e veleidades de consumidores de bens e serviços que acabaram negados a ele próprio.

\section{A carne: as interdiscursividades da insustentabilidade}

O trabalho de Paul Safranek, não por acaso, é o de terapeuta ocupacional na indústria frigorífica. Pelo contrário, a referência intertextual não poderia ser melhor construída, haja vista que se trata do segmento produtivo mais visado pela crítica ambientalista contemporânea. Paul, que tece socialmente e para si mesmo uma débil e vacilante defesa discursiva de sua opção pelo encolhimento como uma contribuição para o bem da saúde planetária, convive cotidianamente com a indústria frigorífica sem sinalizar o mínimo nível de consciência sobre seus impactos e consequências sobre a crise climática.

Ao longo dos anos, importantes cadeias globais de valor vêm sendo esmiuçadas e publicamente denunciadas pela sua insustentabilidade socioeconômica e ambiental, especialmente quando se envolvem a manutenção e a exploração de seus trabalhadores em condições análogas às da escravidão. Entre elas, há anos, a indústria da carne bovina vem sendo alvo de preocupações e denúncias de relevantes agentes sanitaristas e ambientalistas de várias partes do mundo. Contribuem para isso as ameaças da atividade ao desmatamento de florestas e suas altas taxas de emissões de gases de efeito estufa. Para combater tais eventos, reduções no consumo da carne vermelha vêm sendo solicitadas, e diferentes campanhas 
educativas e medidas orientativas são adotadas com o respaldo de autoridades médicas e nutrólogos, de diferentes linhas e orientações, em saúde coletiva e dietética. Relações entre alto consumo de carnes vermelhas e incidências de cardiopatias, colesterol elevado, pressão alta e doenças degenerativas, como vários tipos de câncer, parecem não encontrar mais espaço para refutações científicas.

A necessidade da atenção constante para não sofrer ferimentos graves, sob a demanda de um semnúmero de operações sequenciais e ininterruptas, em nada difere do ambiente da indústria fordista já retratado pela filósofa francesa Simone Weil (1909-1943) a partir de sua experiência de trabalho como operária nas fábricas de Alshton e Renault, em Paris, entre os anos de 1934 e 1936.

Movimentos ativistas como o vegetarianismo e o veganismo, em diferentes frentes, somam esforços na direção da diminuição ou, até mesmo, eliminação total dos abates animais. No entanto, mesmo no contexto pandêmico atual, o comportamento do consumidor parece não arrefecer em relação à demanda por carne, provocando, ao contrário, escassez e subida de preços frente à necessidade sanitária de redução momentânea de abates e transporte de carnes frigorificadas.

Mais uma vez, o discurso irônico se estabelece na trama narrativa, funcionando como estratégia argumentativa no complexo jogo do processo comunicativo.

\section{A redenção pela solidariedade}

Em Downsizing, outra dimensão intertextual também emerge: a dos diálogos com a chamada “legitimidade solidarista” contemporânea (LAVAL, 2020, p. 465). Trata-se de uma perspectiva política na qual indivíduos, de forma crescente, se tornam mais sensíveis e atuantes em relação às causas comuns e à consciência da dependência mútua entre sujeitos e entre populações, para além dos estados e das fronteiras nacionais. Nesse contexto, a solidariedade se instaura como uma nova forma de coexistência entre humanos e não-humanos, consolidando alternativas para a habitação do mundo para além da dominação da natureza. Contra a ameaça iminente do colapso do mundo pelos avanços do capitalismo industrial na destruição metódica e constante dos recursos e condições de existência, propugna-se, nesse contexto, por um saber ecológico holístico que dê conta de instaurar novos saberes e novas práticas simultâneas em relação ao meio 
ambiente, às relações sociais e às subjetividades (GUATTARI, 1990). Assim, visa-se recuperar a ideia, os princípios e as perspectivas do cuidado de todas as dimensões da vida (STENGERS, 2015).

Nesse sentido, o filme - a partir de sua narrativa distópica e de sua discursividade irônica - cumpre seu "objetivo social", conforme propugnado por Göyrgy Lukacs (1971, p. 13-14):

Si un film como obra de arte, ha logrado hacer que la gente reflexione seriamente sobre una situación del pasado o del presente, ha logrado su objetivo. [...]. El film tiene el deber de representar los aspectos positivos y negativos de la sociedad, y, como en ese plano puede tener un relieve esencial, debe lograr que el hombre de la calle reflexione atentamente y con cuidado ya que generalmente suele tocar los temas por encima y sin reflexionar, reaccionando únicamente en el plano sentimental. Si en el cine, una persona sobre diez logra encontrar su propio camino, el film ha logrado su objetivo ${ }^{5}$.

\section{Considerações finais}

Downsizing constitui-se em uma obra de ficção científica distópica que, em sua narrativa leve, cômica e metafórica, propõe e estimula reflexões profundas sobre a condição humana.

Ao mesmo tempo que, pelo caminho das intertextualidades às vezes diretas, outras sutis, denuncia a inércia e a subordinação dos indivíduos aos ditames de um capitalismo insone e irrefreado em suas apropriações da ciência e da técnica, aponta também para uma saída possível, a partir do caminho da solidariedade social.

O filme questiona as efetivas oportunidades e possibilidades da mudança social, mesmo quando uma nova realidade possa oferecer um caminho para a experimentação, para a fabulação de novos imaginários politicamente possíveis e o exercício da invenção social. Nesse sentido, a narrativa sucumbe à desesperança.

A perspectiva guattariana da máquina autopoiética, nessa ficção, não se realiza, na justa medida em que aborta as possibilidades de elaboração do novo, do estranho, do ainda não conhecido e reinstaura todas as vicissitudes do mundo a caminho do colapso. No entanto, em um último sopro de inspiração para o futuro coletivo do mundo e no mundo, o filme aponta para a porta da solidariedade.

\footnotetext{
5 "Se um filme como obra de arte conseguiu fazer as pessoas pensarem seriamente sobre uma situação do passado ou do presente, ele atingiu seu objetivo. [...]. O filme tem o dever de representar os aspectos positivos e negativos da sociedade e, como neste plano pode ter uma relevância essencial, deve fazer com que o homem da rua reflita com atenção e cuidado, pois geralmente tende a tocar nas questões acima sem refletir, reagindo apenas no plano sentimental. Se no cinema uma pessoa em cada dez consegue encontrar o seu caminho, o filme atingiu o seu objetivo" (tradução nossa).
} 
Antonio Hélio Junqueira

ORCID: https://orcid.org/0000-0002-1875-9133

Universidade Federal do Paraná, Programa de Pós-Graduação em Gestão da Informação, Curitiba (PR), Brasil Doutor em Ciências da Comunicação (ECA/USP) E-mail: helio@hortica.com.br

Recebido em: 2 de abril de 2021.

Aprovado em: 3 de maio de 2021.

\section{Referências}

ARAGÃO, M. L. P. de. A paródia em “A força do destino". Revista Tempo Brasileiro, n.62, p.18--28, jul./set. 1980.

BAKHTIN, Mikhail Mikhailovich. A cultura popular na Idade Média e no Renascimento: o contexto de François Rabelais. São Paulo 7 ed. Hucitec, 2010

. Marxismo e filosofia da linguagem. São Paulo: Hucitec, 1995.

BAUMAN, Zigmund. Vida de consumo. Buenos Aires: Fondo de Cultura Económica, 2011.

CÁCERES, André. Mestre da fiç̧ão climática, Kim Stanley Robinson imagina mundo pós-aquecimento global. O Estado de São Paulo, p. H3, 1 de fevereiro de 2020.

DELEUZE, Gilles; GUATTARI, Felix. Kafka: por uma literatura menor. Rio de Janeiro: Imago, 1977.

EAGLETON, Terry. A ideologia da estética. Rio de Janeiro: Jorge Zahar Ed., 1993.

ELLUL, Jacques. The technological order. Proceedings of the Encyclopedia Britannica Conference on the Technological Order. Technology and Culture. Wayne State University Press, Detroit, Michigan, v. 3, n. 4, p. 394-421, 1963

ILLICH, Ivan. A convivencialidade. Lisboa: Publicações Europa - América, 1976.

GIDDENS, Anthony. A política da mudança climática. Rio de Janeiro: Zahar, 2010.

GORE, Albert. A Terra em balanço: ecologia e espírito humano. São Paulo: Augustus, 1993. 
GUATTARI, Félix. As três ecologias. Campinas: Papirus, 1990.

Psicoanalisis y transversalidad. Buenos Aires: Siglo XXI, 1976.

HARVEY, D. Condição pós-moderna. São Paulo: Edições Loyola, 1992.

JUNQUEIRA, Antonio Hélio. A gula de Flusser e o futuro ultratecnológico da comida: entre a ficção científica e a ciência ficcional". Intexto - Edição Especial: Dossiê Flusser - 100 anos, Porto Alegre, UFRGS, p. 280-299, 2020.

KLEIN, Naomi. This changes everything: capitalism vs the climate. New York: Simon \& Schuster, 2014.

LATOUCHE, Serge. Pequeno tratado do decrescimento sereno. Lisboa: Edições 70, 2012.

LAVAL, Christian. Habitar ou dominar: as lições de uma tragédia. In: FRESSATO, Soleni Biscouto; NÓVOA, Jorge (Orgs.). Soou o alarme: a crise do capitalismo para além da pandemia. São Paulo: Perspectiva, 2020.p. 461-473

LUKACS, Göyrgy. El cine como linguaje crítico. Nuevos Aires, ano 2. n .5, set./nov. 1971.

MARQUES FILHO, Luiz César. Capitalismo e colapso ambiental. Campinas: Editora da Unicamp, 2018.

MATURANA, Humberto; VARELA, Francisco. De máquinas y seres vivos. Autopoieses: la organización de lo vivo. Santiago do Chile: Editorial Universitária, 1998.

NEBRASKA. Direção: Alexander Payne. Produção: Albert Berger; Ron Yerxa. Estados Unidos da América: Paramount \& Bona Fide Production, 2013. (DVD). (110 min).

O INCRÍVEL HOMEM QUE ENCOLHEU (The incredible shrinkin man”). Direção: Jack Arnold. Produção: Albert Zygsmith. Estados Unidos da América, 1957. (DVD). (81 min).

QUERIDA, ENCOLHI AS CRIANÇAS (Honey, I shrunk the kids). Direção: Joe Johnston. Produção: Penny Finkelman Cox. Estados Unidos da América: Walt Disney Pictures, 1989. (DVD). (94 min).

REES, Martin. Our final hour: a scientist's warning: how terror, error, and environmental disaster threaten humankind's future in this century - on earth and beyond. New York: Basic Books, 2003.

SANDAGE, Scott A. Born losers: a history of failure in America. Boston: Harvard University Press, 2005

SANT'ANNA, Affonso Romano. Paródia, paráfrases \& Cia. São Paulo: Editora Ática, 2003. (Série Princípios).

SFEZ, Lucien. A saúde perfeita: crítica de uma nova utopia. São Paulo: Edições Loyola, 1996.

STENGERS, Isabelle. No tempo das catástrofes - resistir à barbárie que se aproxima. São Paulo: Cosac Naif, 2015. 
WEIL, Simone. A condição operária e outros escritos sobre a opressão. Org. por Ecléa Bosi. Rio de Janeiro: Paz e Terra, 1979.

\section{Resumo}

O artigo discute, a partir da crítica de uma obra ficcional, as dimensões discursivas da ironia na narrativa distópica do futuro, no qual a vida humana e a própria sobrevivência do planeta encontramse ameaçadas pelo avanço inexorável do consumismo, do progresso capitalista e dos seus impactos sobre a crise climática global. Metodologicamente, o texto explora os conceitos bakhtinianos da linguagem do riso na conformação dos sentidos sociais, buscando identificar seu potencial enquanto estratégia argumentativa. A análise aponta para a eficácia discursiva da ironia para abordar o comportamento humano irremovível frente às promessas dos prazeres inesgotáveis do lazer permanente e do consumismo e o fracasso da máquina autopoiética guattariana na produção de novas subjetividades e do agenciamento coletivo para a produção de novas realidades, ambos fenômenos necessários ao enfrentamento do iminente colapso ambiental.

Palavras-chave: Narrativas Distópicas. Futuro. Ficção Científica. Discurso.

\section{Abstract}

The article discusses, from the critique of a fictional work, the discursive dimensions of irony in the dystopian narrative of the future, in which the inexorable advance of consumerism, capitalist progress and its impacts on the global climate crisis threatens human life and the very survival of the planet. Methodologically, the text explores the Bakhtinian concepts of the language of laughter in shaping the social senses, seeking to identify its potential as an argumentative strategy. The analysis points to the discursive efficacy of irony to address irremovable human behavior in the face of the pleasures of the inexhaustible pleasures of permanent leisure and consumerism and the failure of the Guattarian autopoietic machine in the production of new subjectivities and collective agency for the production of new realities, both phenomena necessary to face the imminent environmental collapse. 
Keywords: Dystopian Narratives. Future; Science Fiction. Discourse.

\section{Resumen}

El artículo analiza, a partir de la crítica de una obra de ficción, las dimensiones discursivas de la ironía en la narrativa distópica del futuro, en que la vida humana y la propia supervivencia del planeta se ven amenazadas por el inexorable avance del consumismo, el progreso capitalista y sus impactos sobre la crisis climática global. Metodológicamente, el texto explora los conceptos bajtinianos del lenguaje de la risa en la configuración de los sentidos sociales, buscando identificar su potencial como estrategia argumentativa. El análisis apunta a la eficacia discursiva de la ironía para abordar el comportamiento humano inamovible frente a los placeres inagotables del ocio y el consumismo permanentes y el fracaso de la máquina autopoiética guattarana en la producción de nuevas subjetividades y agencia colectiva para la producción de nuevas realidades, ambos fenómenos necesarios para afrontar el inminente colapso ambiental.

Palabras clave: Narrativas Distópicas. Futuro. Ficción Científica. Discurso.

Este artigo é publicado em acesso aberto (Open Access) sob a licença Creative Commons Attribution Non-Commercial (CC-BY-NC 4.0), que permite que outros remixem, adaptem e criem a partir do seu trabalho para fins não comerciais, e embora os novos trabalhos tenham de Ihe atribuir o devido crédito e não possam ser usados para fins comerciais, os usuários não têm de licenciar esses trabalhos derivados sob os mesmos termos. 